\title{
ATRIBUTOS FÍSICOS DO ARGISSOLO AMARELO DO SEMIÁRIDO NORDESTINO SOB SISTEMAS DE PREPARO ${ }^{(1)}$
}

\author{
Jorge Wilson Cortez ${ }^{(2)}$, Aline Dantas da Silva Alves ${ }^{(3)}$, Marcelo \\ Rubens Dias de Moura ${ }^{(3)}$, Nelci Olszevski ${ }^{(2)}$ \& Hideo de Jesus
}

Nagahama ${ }^{(4)}$

\begin{abstract}
RESUMO
Os sistemas de preparo do solo devem propiciar boas condições físicas do solo, para que as plantas possam se desenvolver adequadamente. O objetivo deste trabalho foi avaliar densidade, porosidade e resistência mecânica à penetração em Argissolo Amarelo do semiárido nordestino após preparo com quatro implementos agrícolas (escarificador, grade leve em tandem, grade leve off-set com discos de 0,56 m e grade leve off-set com discos de 0,61 m) em uma, duas e três operações, usando como testemunha uma área sem preparo. Os dados de densidade e de porosidade do solo foram analisados pela estatística clássica, e os dados de resistência à penetração, pela geoestatística, utilizando-se uma malha composta pela largura do equipamento e pela profundidade de $0,40 \mathrm{~m}$. $\mathrm{O}$ efeito do preparo do solo foi pouco expressivo sobre as características avaliadas. Verificaram-se maiores valores de densidade apenas na camada de 0,10-0,20 m para todos os equipamentos avaliados. A porosidade variou em função dos equipamentos, sendo maior no tratamento sem preparo e menor no preparo com escarificador e com grade leve off-set com discos de $0,61 \mathrm{~m}$ de diâmetro; a camada de 0,20-0,30 m apresentou menor porosidade. A resistência à penetração mostrou valores adequados na profundidade de trabalho de cada equipamento e foi alta nas camadas situadas abaixo, exceto no preparo do solo com escarificador.
\end{abstract}

Termos de indexação: densidade do solo, preparo do solo, geoestatística.

\footnotetext{
(1) Recebido para publicação em 21 de junho de 2010 e aprovado em 30 de maio de 2011.

(2) Professor Adjunto, Universidade Federal do Vale do São Francisco - UNIVASF. Av. José de Sá Maniçoba s/n, Centro, Petrolina (PE). E-mails: jorge.cortez@univasf.edu.br; nelci.olszevski@univasf.edu.br

(3) Egresso do curso de Zootecnia da UNIVASF. E-mails: alineunivasf@gmail.com; mrdmoura@yahoo.com.br

(4) Eng. Agrônomo, Chefe da Seção de Apoio às Atividades de Campo da Fazenda Experimental da UNIVASF. E-mail: hideo.nagahama@univasf.edu.br
} 


\title{
SUMMARY: PHYSICAL PROPERTIES OF YELLOW ARGISOL IN THE SEMI ARID REGION OF NORTHEASTERN BRAZIL UNDER TILLAGE SYSTEMS
}

\begin{abstract}
Tillage systems should create adequate conditions for plant development. The objective of this study was to evaluate the density, porosity and penetration resistance of a Yellow Ultisol in the semi-arid region of northeastern Brazil after tilling with four agricultural implements (chisel, tandem disc harrow, offset disc harrow with $0.56 \mathrm{~m}$ discs, offset disc harrow with $0.61 \mathrm{~m}$ discs) in one, two and three operations, using an area without tillage as control. Data of soil bulk density and porosity were analyzed by classical statistics and penetration resistance by geostatistics using a grid given by the width of the equipment and reaching depth of $0.40 \mathrm{~m}$. The effect of tillage had little influence on the evaluated properties. Higher bulk density values were detected in the 0.10-0.20 m layer only for all tilling devices. Porosity varied according to tilling, i.e., values were highest in the untilled soil and lower in soil that was chisel-tilled and harrowed with $0.61 \mathrm{~m}$ offset discs; porosity was lowest in the 0.20-0.30 m layer. The values of penetration resistance were adequate at the reaching depth of each equipment and high in the layers underneath, except in chisel-tilled soil.
\end{abstract}

Index terms: soil bulk density, tillage, geostatistics.

\section{INTRODUÇÃO}

Do ponto de vista técnico, o sistema de manejo deve contribuir para a manutenção ou melhoria da qualidade do solo e do ambiente, bem como para a obtenção de produtividade satisfatória das culturas no longo prazo (Costa et al., 2003). Com esse intuito, são realizadas mobilizações de solo que desencadeiam reações integradas nos processos biológicos, químicos e físicos (Sumner, 1992). Contudo, essas mobilizações podem promover alterações indesejáveis na estrutura da camada arável, como aumento na resistência à penetração e na densidade do solo e redução na macroporosidade e na taxa de infiltração de água (Spera et al., 2009).

O manejo do solo pode modificar suas propriedades físicas, dependendo da intensidade de preparo do solo (Souza et al., 2001), e essas modificações, por vezes, não promovem resultados satisfatórios. A compactação do solo aumenta a sua densidade e a resistência mecânica (Hillel, 1982; Wagger \& Denton, 1989; Hill \& Meza-Montalvo, 1990; Lebert \& Horn, 1991; Silva et al., 2006) e diminui a porosidade total e o tamanho e continuidade dos poros (Hillel, 1982; Smucker \& Erickson, 1989; Dexter, 2004). Reduções significativas ocorrem principalmente no volume dos macroporos, enquanto os microporos permanecem praticamente inalterados (Hillel, 1982). A compactação do solo pode limitar a adsorção e, ou, absorção de nutrientes, a infiltração e a redistribuição de água, as trocas gasosas e o desenvolvimento do sistema radicular (Grohmann \& Queiroz Neto, 1966; Alvarenga et al., 1983; Bicki \& Siemens, 1991), resultando em decréscimo da produção e aumento da erosão e da potência necessária para o preparo do solo (Soane, 1990).
A formação e, ou, presença de zonas de maior compactação têm sido avaliadas pela resistência mecânica do solo à penetração (Beutler et al., 2007), sendo fundamental que se faça o monitoramento dos dados de densidade do solo, uma vez que esse fator influencia diretamente os valores da resistência mecânica (Mercante et al., 2003). Além disso, a resistência do solo à penetração é uma das propriedades físicas do solo diretamente relacionadas com o crescimento das plantas (Letey, 1991) e modificada pelos sistemas de preparo do solo. Como o preparo do solo não é uniforme em toda a área, é importante avaliar a distribuição espacial dos valores das suas características (Souza et al., 2001), pois valores muito elevados de resistência do solo à penetração podem influenciar o crescimento das raízes em comprimento e diâmetro (Merotto \& Mundstock, 1999) e a direção preferencial do crescimento radicular (Iijima \& Kono, 1991), além de alterar a dinâmica da água e de nutrientes no solo.

O objetivo deste trabalho foi avaliar a densidade, porosidade e resistência mecânica do solo à penetração em um Argissolo Amarelo no semiárido nordestino após mecanização com diferentes implementos agrícolas e diferentes números de operações, comparando-os com uma área sem preparo.

\section{MATERIAL E MÉTODOS}

O trabalho foi instalado no Campus de Ciências Agrárias da Universidade Federal do Vale do São Francisco (UNIVASF), que está situado dentro do Projeto de Irrigação Senador Nilo Coelho, em Petrolina 
- PE. A área experimental está localizada em latitude de $09^{\circ} 19^{\prime} 16$ " sul e longitude de $40^{\circ} 33^{\prime} 43$ " oeste, a uma altitude de $373 \mathrm{~m}$. Segundo Brasil (1973), utilizando a classificação de Köppen, o clima da região é tropical semiárido, tipo BSwh, caracterizado pela escassez e irregularidade das precipitações, com chuvas no verão e forte evaporação em consequência das altas temperaturas. O solo foi classificado como Argissolo Amarelo Distrófico típico, textura arenosa/média (Quadro 1) por Amaral et al. (2006), utilizando o Sistema Brasileiro de Classificação de Solos (Embrapa, 2006). A área de instalação do experimento possui sistema linear de irrigação, visando à manutenção da umidade do solo no momento do preparo e durante a coleta de dados.

Foi utilizado o delineamento em blocos ao acaso com parcelas subdivididas, com quatro repetições. Os cinco tratamentos de preparo, aplicados nas parcelas principais, foram: sem preparo e preparo com escarificador, grade leve em tandem, grade leve offset com discos de 0,56 m (22") de diâmetro e grade leve off-set com discos de 0,61 m (24") de diâmetro. Nas subparcelas, foram aplicadas uma, duas e três operações de mobilização do solo, com cada equipamento. Cada parcela experimental ocupou área de $20 \times 10 \mathrm{~m}\left(200 \mathrm{~m}^{2}\right)$. No sentido longitudinal entre as parcelas, foi reservado um espaço de $15 \mathrm{~m}$, destinado à realização de manobras, tráfego de máquinas e estabilização dos conjuntos.

Os implementos utilizados no preparo do solo foram: (a) grade leve em tandem com sete discos em cada uma das quatro seções, num total de 14 discos recortados na dianteira e 14 lisos na traseira, com diâmetro de 0,51 m (20"), distância entre discos de $0,19 \mathrm{~m}$, largura de $2,62 \mathrm{~m}$, massa de $528 \mathrm{~kg}$ e profundidade de trabalho de 0,10 m; (b) grade leve offset com oito discos em cada uma das duas seções, num total de 16 discos recortados com $0,56 \mathrm{~m}$ de diâmetro (22"), distância entre discos de 0,23 m, largura de $1,73 \mathrm{~m}$, massa de aproximadamente $1.000 \mathrm{~kg}$ e profundidade de trabalho de $0,15 \mathrm{~m}$; (c) grade leve offset com sete discos em cada uma das duas seções, no total de 14 discos recortados com diâmetro de $0,61 \mathrm{~m}$ (24"), distância entre discos de 0,23 m, largura de $1,50 \mathrm{~m}$, massa de $1.094 \mathrm{~kg}$ e profundidade de trabalho 0,18 m; e (d) escarificador com três hastes espaçadas

Quadro 1. Composição granulométrica para as profundidades do Argissolo Amarelo

\begin{tabular}{cccc}
\hline Profundidade & Argila & Areia & Silte \\
\hline $\mathrm{m}$ & & $\mathrm{kg} \mathrm{kg}^{-1}$ & \\
$0,00-0,10$ & 0,090 & 0,878 & 0,032 \\
$0,10-0,20$ & 0,100 & 0,883 & 0,017 \\
$0,20-0,30$ & 0,080 & 0,852 & 0,068 \\
$0,30-0,40$ & 0,140 & 0,807 & 0,053 \\
$0,40-0,50$ & 0,180 & 0,742 & 0,078 \\
\hline
\end{tabular}

de 0,34 m, ponteira estreita de 0,05 m, largura total de $1,20 \mathrm{~m}$, massa de $295 \mathrm{~kg}$ e profundidade de trabalho de até $0,35 \mathrm{~m}$.

Como fonte de potência para tracionar os equipamentos de preparo do solo foi utilizado um trator modelo 785 TDA (tração dianteira auxiliar), com $55,20 \mathrm{~kW}(75 \mathrm{cv})$ de potência, com pneus dianteiros 12.4-24 R1 e traseiros 18.4-30 R1, sendo utilizada a rotação de trabalho no motor de 2.040 rpm (rotações por minuto).

$\mathrm{Na}$ análise de densidade do solo (Ds) foi usado o método do anel volumétrico, com anéis de $0,05 \mathrm{~m}$ de altura e 0,0508 m (2") de diâmetro e volume total de $101,33 \mathrm{~cm}^{3}$. As amostras foram secas em estufa à temperatura de $105-110{ }^{\circ} \mathrm{C}$ até se obter massa constante, sendo posteriormente pesadas, para obtenção dos valores de Ds (Embrapa, 1997). A porosidade total determinada (PT) foi obtida após os anéis terem sido colocados em uma bandeja com água até atingirem o ponto de saturação, sendo pesados novamente; a partir daí, obteve-se a porosidade total determinada, segundo Camargo et al. (1986). A coleta das amostras foi em um ponto aleatório dentro de cada subparcela, nas camadas de 0,00-0,10, 0,10-0,20 e $0,20-0,30 \mathrm{~m}$ de profundidade.

Os dados de densidade e de porosidade total determinada do solo foram submetidos à análise de variância para cada camada individualmente; quando observada significância estatística a pelo menos $5 \%$, foi utilizado o teste de Tukey para comparação de médias (Banzatto \& Kronka, 2006). Para comparação entre camadas de solo, consideraram-se as repetições de cada equipamento e operação separadamente.

Para análise da resistência mecânica do solo à penetração $(\mathrm{RP})$, utilizou-se um penetrômetro de impacto modelo IAA/Planalsucar-Stolf, desenvolvido por Stolf et al. (1983), com as seguintes características: massa de $4 \mathrm{~kg}$ com impacto em curso de queda livre de 0,40 m; cone com 0,0128 m de diâmetro e ângulo sólido de $30^{\circ}$; e haste com diâmetro aproximado de $0,01 \mathrm{~m}$. A coleta de dados foi realizada com a umidade do solo próxima à da capacidade de campo, tomandose como base a largura de trabalho de cada equipamento. Com o intuito de identificar zonas de maior RP nas camadas após o preparo com os equipamentos, foram coletados dados a cada $0,20 \mathrm{~m}$ dentro da faixa de trabalho do equipamento. Os dados de RP foram anotados até a profundidade de 0,40 $\mathrm{m} \mathrm{e}$ transformados em MPa (Stolf, 1991).

Para análise dos dados da RP, utilizou-se a estatística descritiva e a geoestatística. A estatística descritiva permitiu a visualização geral do comportamento dos dados, obtendo-se os valores mínimo, médio e máximo, desvio-padrão, variância, assimetria e "kurtose" para RP. Na geoestatística, foram construídos semivariogramas, partindo das pressuposições de estacionaridade da hipótese intrínseca, do cálculo da função semivariância e de ajustes dos modelos teóricos (Vieira, 2000). No ajuste 
do semivariograma foi observado o maior valor do coeficiente de determinação $\left(R^{2}\right)$, menor valor da soma de quadrados dos desvios (RSS) e maior valor do avaliador dependência espacial (ADE). O ajuste do semivariograma foi realizado "a sentimento", selecionando-se o modelo e seus parâmetros, sobrepondo-o aos pontos estimados e verificando-se visualmente sua adequação. Os semivariogramas forneceram estimativas dos parâmetros: efeito pepita $\left(\mathrm{C}_{0}\right)$, patamar $\left(\mathrm{C}_{0}+\mathrm{C}\right)$ e alcance $(\mathrm{Ao})$. A análise da dependência espacial (ADE) foi efetuada segundo método descrito por Landim (1998). Em seguida à modelagem dos semivariogramas, foi realizada a interpolação por "krigagem" ordinária, para estimativa de valores em locais não amostrados.

\section{RESULTADOS E DISCUSSÃO}

\section{Densidade do solo (Ds) e porosidade total (Pt)}

Os valores de Ds oscilaram entre 1,30 e 1,43 $\mathrm{Mg} \mathrm{m}^{-3}$ nas parcelas submetidas aos sistemas de preparo do solo e ao número de operações, considerando-se todas as camadas avaliadas (Quadro 2), porém a interação dos fatores (preparo e operações) não foi significativa. Observaram-se valores médios de Ds mais altos na camada de 0,10-0,20 m, com variações não significativas entre os sistemas de preparo, indicando ser essa uma característica intrínseca do solo para essa camada, já que os valores não se diferenciaram entre os sistemas de preparo. Para a Ds nas camadas em relação ao número de operações, não se observou diferença significativa.

\section{Quadro 2. Densidade do solo em quatro tratamentos de preparo do solo aplicados em três intensidades, em três camadas amostradas}

\begin{tabular}{lccc}
\hline \multirow{2}{*}{ Fatores } & \multicolumn{3}{c}{ Densidade do solo $\left(\mathbf{M g ~ m}^{-3}\right)$} \\
\cline { 2 - 3 } & $\mathbf{0 , 0 0 - 0 , 1 0 ~} \mathbf{~ m}$ & $\mathbf{0 , 1 0 - 0 , 2 0} \mathbf{~ m}$ & $\mathbf{0 , 2 0 - 0 , 3 0 ~} \mathbf{~ m}$ \\
\hline Preparo (P) & \multicolumn{3}{c}{} \\
Escarificador & $1,30^{\mathrm{ns}}$ & $1,38^{\mathrm{ns}}$ & $1,35^{\mathrm{ns}}$ \\
Grade leve em tandem & 1,38 & 1,43 & 1,41 \\
Grade leve off-set 0,56 m & 1,38 & 1,36 & 1,36 \\
Grade leve off-set $0,61 \mathrm{~m}$ & 1,38 & 1,41 & 1,40 \\
Sem preparo & 1,37 & 1,40 & 1,40 \\
Média & $1,37 \mathrm{~B}$ & $1,42 \mathrm{~A}$ & $1,37 \mathrm{~B}$ \\
Operações (O) & & & \\
Uma & 1,40 & 1,43 & 1,37 \\
Duas & 1,35 & 1,39 & 1,40 \\
Três & 1,34 & 1,37 & 1,38 \\
Média & $1,36^{\mathrm{ns}}$ & 1,40 & 1,38 \\
CV (\%) Preparo & 12,40 & 14,50 & 12,00 \\
CV (\%) Operações & 6,80 & 6,80 & 8,00 \\
\hline
\end{tabular}

Médias seguidas de mesmas letras minúsculas, na coluna, e letras maiúsculas, na linha, não diferem entre si (Tukey $\mathrm{p}<0,05)$. ns: não significativo $(\mathrm{p}>0,05)$. CV: coeficiente de variação.
Os valores de densidade do Argissolo estudado podem ser considerados não críticos, uma vez que vários autores também encontraram valores mais altos para esse atributo em Argissolos de textura superficial mais arenosa. Torres \& Saraiva (1999) observaram valores de densidade de 1,25 a $1,70 \mathrm{Mg} \mathrm{m}^{-3}$ para solos arenosos do Paraná. Araujo et al. (2004) verificaram para Argissolo Amarelo distrófico, com textura superficial média, que os valores de densidade em área de mata variaram de 1,40 a 1,64 $\mathrm{Mg} \mathrm{m}^{-3}$, ao passo que Silva et al. (2002), em Argissolos Amarelos de textura média/argilosa da região de Petrolina $-\mathrm{PE}$, encontraram valores de 1,46 a $1,50 \mathrm{Mg} \mathrm{m}^{-3}$ nos horizontes $\mathrm{A}$ e $\mathrm{AB}$ e de 1,66 a $1,91 \mathrm{Mg} \mathrm{m}^{-3}$ no horizonte $\mathrm{Bt}$, para áreas sem preparo.

A porosidade total determinada $(\mathrm{Pt})$, propriedade que tem relação estreita e inversa com a Ds, apresentou valores médios similares entre os sistemas com preparo do solo para as camadas de $0,10-0,20$ e 0,20-0,30 m de profundidade (Quadro 3), o que demonstra que os diferentes implementos alteraram de modo similar esse atributo nessas camadas. A interação dos fatores (preparo e operações) não foi significativa. Para a camada de 0,00-0,10 m, observou-se maior porosidade na área sem preparo, não se diferenciando da grade leve em tandem e da grade leve off-set com discos de 0,56 m de diâmetro, mas diferenciando-se da grade leve off-set com discos de 0,61 m de diâmetro e do escarificador, em que os valores de $\mathrm{Pt}$ foram mais baixos.

O escarificador é um equipamento de preparo do solo em que o trabalho ocorre por ação das hastes, sem a inversão da leiva, tornando-se menos agressivo à estrutura e com menor capacidade de reversão das camadas do solo, reduzindo a compactação de forma mais localizada. Por ter maior capacidade de penetração e por causar menor desagregação do solo, em relação aos arados e grades de discos (Araújo, 1999), tem sido bastante utilizado no sistema de preparo ano após ano sem provocar impedimentos mecânicos. Apesar disso, promoveu ligeira redução da Pt no solo estudado.

Os valores de Pt encontrados assemelham-se aos obtidos por Araújo et al. (2004), os quais verificaram, em Argissolo Amarelo Distrófico de textura média em superfície do Estado do Acre, que os valores de Pt variaram de 0,36 a 0,44 nos horizontes $\mathrm{A}$ e $\mathrm{AB}$ do solo sob diferentes usos agrícolas, muito abaixo dos valores de $0,80 \mathrm{~m}^{3} \mathrm{~m}^{-3}$ encontrados em área de mata. Silva et al. (2002) obtiveram valores de $\mathrm{Pt}$ variando de 0,42 a $0,44 \mathrm{~m}^{3} \mathrm{~m}^{-3} \mathrm{em}$ Argissolo Amarelo de textura média/ argilosa, no município de Petrolina - PE, na camada de 0 a $32 \mathrm{~cm}$ do solo sem preparo.

A Pt média do solo diminuiu com a profundidade, sendo o menor valor encontrado na camada de $0,20-$ $0,30 \mathrm{~m}$, porém isso tem pouco valor prático, uma vez que o valor médio $\left(0,43 \mathrm{~m}^{3} \mathrm{~m}^{-3}\right)$ é praticamente igual ao do solo sem preparo. O número de operações não influenciou a Pt, apesar do aumento no número de 
Quadro 3. Porosidade total determinada do solo em quatro tratamentos de preparo do solo aplicados em três intensidades, em três camadas amostradas

\begin{tabular}{|c|c|c|c|}
\hline \multirow{2}{*}{ Fatores } & \multicolumn{3}{|c|}{ Porosidade total do solo $\left(\mathrm{m}^{3} \mathrm{~m}^{-3}\right)$} \\
\hline & $0,00-0,10 \mathrm{~m}$ & $0,10-0,20 \mathrm{~m}$ & $0,20-0,30 \mathrm{~m}$ \\
\hline \multicolumn{4}{|l|}{ Preparo (P) } \\
\hline Escarificador & $0,43 \mathrm{~b}$ & $0,44 \mathrm{~ns}$ & $0,42 \mathrm{~ns}$ \\
\hline Grade leve em tandem & $0,45 \mathrm{ab}$ & 0,47 & 0,40 \\
\hline Grade leve off-set $0,56 \mathrm{~m}$ & $0,46 \mathrm{ab}$ & 0,46 & 0,44 \\
\hline Grade leve off-set $0,61 \mathrm{~m}$ & $0,43 \mathrm{~b}$ & 0,45 & 0,45 \\
\hline Sem preparo & $0,48 \mathrm{a}$ & 0,47 & 0,42 \\
\hline Média & $0,45 \mathrm{~A}$ & $0,46 \mathrm{~A}$ & $0,43 \mathrm{~B}$ \\
\hline \multicolumn{4}{|l|}{ Operações (O) } \\
\hline Uma & $0,44^{\mathrm{ns}}$ & $0,45^{\mathrm{ns}}$ & $0,44^{\mathrm{ns}}$ \\
\hline Duas & 0,45 & 0,45 & 0,41 \\
\hline Três & 0,45 & 0,47 & 0,42 \\
\hline Média & $0,44^{\mathrm{ns}}$ & 0,45 & 0,43 \\
\hline CV (\%) Preparo & 8,40 & 12,10 & 20,70 \\
\hline CV (\%) Operações & 10,50 & 9,20 & 15,30 \\
\hline
\end{tabular}

Médias seguidas de mesmas letras minúsculas, na coluna, e letras maiúsculas, na linha, não diferem entre si (Tukey $\mathrm{p}<0,05){ }^{\mathrm{ns}}$ : não significativo $(\mathrm{p}>0,05)$. CV: coeficiente de variação.

passagens do trator com os implementos e do aumento do processo de revolvimento quando do uso das grades, discordando de Soehne (1958), em que o tráfego de trator em solo solto resulta em transmissão de pressão aplicada na superfície até maior profundidade. Provavelmente esse comportamento diferenciado do Argissolo Amarelo tenha ocorrido devido à sua textura superficial excessivamente arenosa - situação em que as variações nos atributos porosidade e densidade são menores, pelo efeito das operações de preparo.

\section{Análise espacial da resistência mecânica do solo à penetração (RP)}

Os valores numéricos da estatística descritiva para os valores médios da RP (média das quatro profundidades) com os equipamentos de preparo e as operações (O1, O2 e O3) indicaram que ocorreu diminuição de $\mathrm{RP}$ em relação à área sem preparo (Quadro 4), em especial para o escarificador, devido à atuação das hastes no solo em ângulos de $45^{\circ}$ para a direita e para a esquerda, bem como para frente, preparando e removendo possíveis zonas de maior RP, com maior eficiência do que as grades. Normalmente, os maiores valores de RP encontram-se abaixo da camada trabalhada, indicando a presença de "pé-de-arado" ou "péde-grade". No entanto, observou-se, de maneira geral, para todos os equipamentos utilizados, valores acima do limite preconizado de 6,0 $\mathrm{MPa}$ para solos arenosos, indicando que em alguns pontos há zonas com RP maior do que a diagnosticada como limitante para o crescimento radicular (Sene et al., 1985). Os maiores valores de RP ocorreram geralmente nas camadas inferiores do solo, conforme será demonstrado adiante pelos resultados da krigagem. Quanto aos dados de assimetria e de kurtose, quanto mais próximos de zero, maior a normalidade dos dados, não sendo necessários para aplicação da geoestatística. No entanto, essa informação facilita o ajuste "a sentimento" do semivariograma.

Quadro 4. Estatística descritiva da resistência mecânica do solo à penetração para os equipamentos de preparo do solo com uma $(\mathrm{O} 1)$, duas $(\mathrm{O} 2)$ e três $(\mathrm{O} 3)$ operações subsequentes

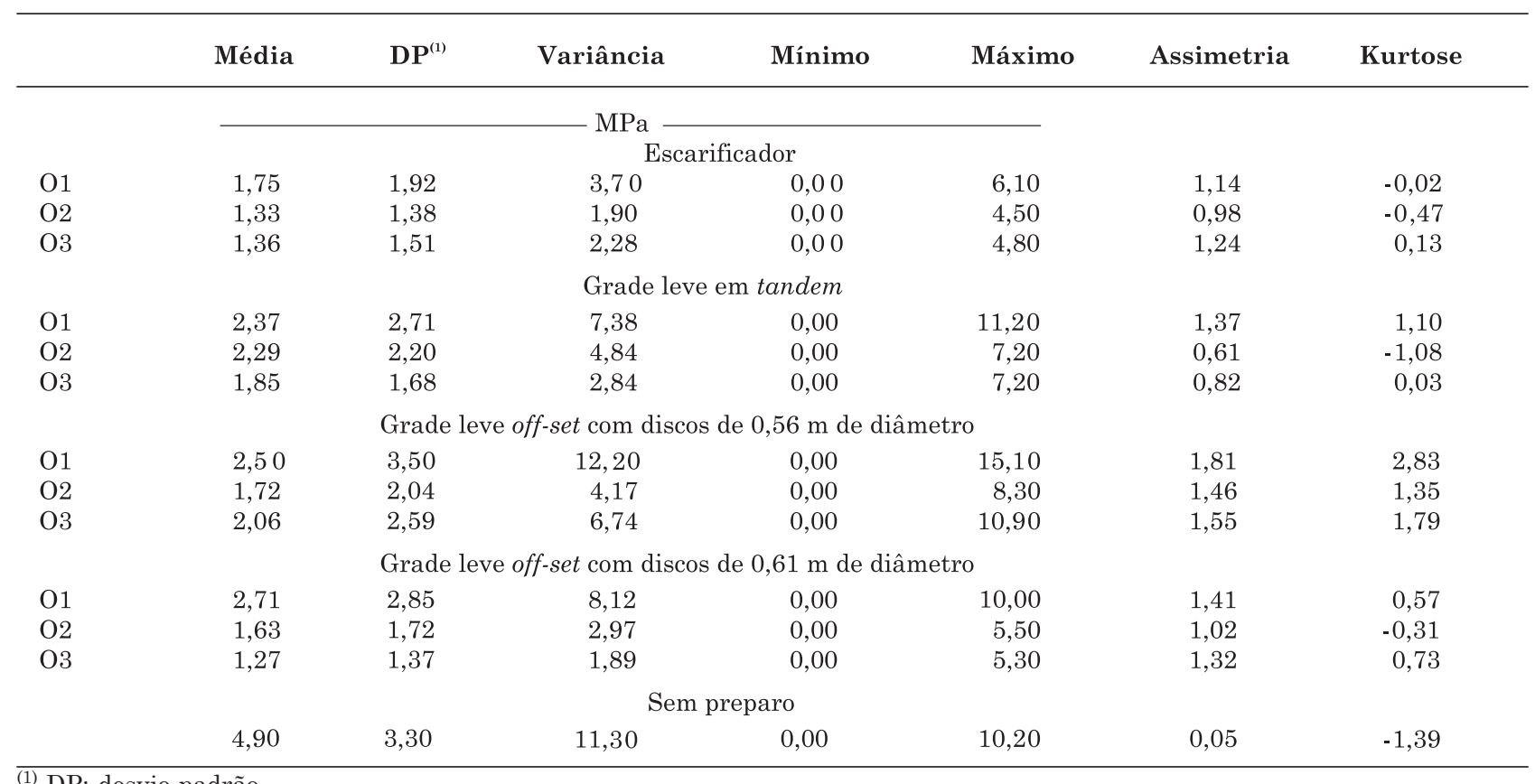

(1) DP: desvio-padrão. 
Para os parâmetros ajustados aos semivariogramas, observa-se que o modelo exponencial explica o comportamento para os dados de RP na área preparada com grade leve off set com discos de 0,56 m de diâmetro com uma operação de preparo, e o modelo esférico explica o comportamento para os demais equipamentos, o número de operações e para a área sem preparo (Quadro 5). Mercante et al. (2003) encontraram semivariogramas exponencial, esférico e exponencial na modelagem de dados de RP para as camadas de $0,00-0,10,0,10-0,20$ e $0,20-0,30 \mathrm{~m}$, respectivamente, para uma área em Latossolo Vermelho com e sem manejo químico. O modelo esférico é o mais utilizado e adequado para representação de variáveis relacionadas à planta e ao solo (Salviano et al., 1998). Esses modelos apresentaram os melhores resultados, pelo alto valor de $\mathrm{R}^{2}$ e menor soma de quadrado de resíduos (RSS), bem como o maior valor do avaliador de dependência espacial (ADE). A dependência espacial observada foi "forte", conforme classes estabelecidas por Landim (1998), em que ADE < $25 \%$ indica correlação fraca; ADE entre 25 e $75 \%$, correlação média; e ADE $>75 \%$, correlação forte. Cambardella et al. (1994) afirmam que a dependência espacial forte dos atributos do solo pode ser atribuída a fatores intrínsecos, como material de origem, relevo, clima, organismos e tempo, ao passo que a dependência espacial fraca pode ser atribuída a fatores extrínsecos, como adubação, calagem, preparo do solo e tráfego de máquinas agrícolas.

$\mathrm{O}$ alcance encontrado nos dados de RP indica que há correlação entre as amostras, variando de 0,43 e $0,77 \mathrm{~m}$; a partir dessa distância os valores são aleatórios, ou seja, não há dependência espacial. O espaçamento de amostragem $(0,20 \mathrm{~m})$ foi adequado para a grade leve off-set com discos de $0,56 \mathrm{~m}$ de diâmetro. No entanto, foi grande para os demais equipamentos, como visualizado no atributo intervalo de dados (Quadro 5). A geoestatística revelou dependência espacial, e sugere-se a utilização do alcance desses atributos na realização de futuras amostragens.

É importante identificar as zonas de maior RP por meio da análise espacial desse atributo no perfil do solo, a fim de estabelecer a profundidade inferior até onde deverá atuar o elemento rompedor, no caso da subsolagem ou escarificação.

$\mathrm{Na}$ área sem preparo, os resultados da krigagem indicam que os valores de RP chegaram a até 4,0 $\mathrm{MPa}$ na camada de $0,30 \mathrm{~m}$ (Figura 1 ). Valores acima de 4,0 $\mathrm{MPa}$ predominaram nas camadas abaixo de $0,30 \mathrm{~m}$ de profundidade, obtendo-se pontos com valores de até 10,0 MPa. Esses valores altos de RP nas camadas mais inferiores podem ser atribuídos à presença de horizontes de maior acumulação de argila, resultantes dos processos de eluviação e iluviação, que os tornam naturalmente mais adensados, o que pode ser confirmado pelo maior teor de argila nas camadas abaixo de 0,30 m (Quadro 1). Abreu et al. (2004) constataram em área sem preparo, em um Argissolo Vermelho-Amarelo, valores de RP máximos de $1,45 \mathrm{MPa}$ até $0,075 \mathrm{~m}$ de profundidade. Verifica-se que o revolvimento do solo na área não seria necessário, pois este apresenta valores de RP apropriados para a adequada elongação radicular (Sene et al., 1985), podendo-se, portanto, utilizar sistemas de manejo como a semeadura direta e o cultivo mínimo (escarificador).

Quadro 5. Parâmetros dos semivariogramas ajustados para a resistência mecânica do solo à penetração para os equipamentos de preparo do solo com uma (O1), duas (O2) e três (O3) operações subsequentes

\begin{tabular}{|c|c|c|c|c|c|c|c|c|c|}
\hline & Modelo & $\mathrm{Co}^{(1)}$ & $\mathrm{Co}+\mathrm{C}^{(2)}$ & $\mathrm{Ao}^{(3)}$ & $\mathrm{ID}^{(4)}$ & $\mathrm{DC}^{(5)}$ & $\mathrm{R}^{2}$ & $\mathrm{RSS}^{(6)}$ & $\mathrm{ADE}^{(7)}$ \\
\hline & \multicolumn{9}{|c|}{ Escarificador } \\
\hline O1 & Esférico & 0,38 & 4,43 & 0,55 & 0,15 & 1,01 & 0,86 & 1,30 & 0,91 \\
\hline $\mathrm{O} 2$ & Esférico & 0,20 & 2,29 & 0,55 & 0,15 & 1,00 & 0,85 & 0,35 & 0,91 \\
\hline $\mathrm{O} 3$ & Esférico & 0,34 & 2,71 & 0,54 & 0,15 & 1,05 & 0,85 & 0,42 & 0,87 \\
\hline \multicolumn{10}{|c|}{ Grade leve em tandem } \\
\hline $\mathrm{O} 1$ & Esférico & 0,61 & 7,22 & 0,44 & 0,17 & 1,31 & 0,82 & 3,68 & 0,92 \\
\hline $\mathrm{O} 2$ & Esférico & 0,01 & 5,17 & 0,46 & 0,17 & 1,31 & 0,87 & 2,12 & 0,99 \\
\hline $\mathrm{O} 3$ & Esférico & 0,01 & 3,07 & 0,43 & 0,18 & 1,31 & 0,89 & 0,47 & 0,99 \\
\hline \multicolumn{10}{|c|}{ Grade leve off-set com discos de 0,56 m de diâmetro } \\
\hline $\mathrm{O} 1$ & Exponencial & 0,01 & 16,43 & 0,36 & 0,22 & 1,41 & 0,96 & 2,78 & 0,99 \\
\hline $\mathrm{O} 2$ & Esférico & 0,01 & 4,75 & 0,55 & 0,21 & 1,41 & 0,90 & 0,73 & 0,99 \\
\hline $\mathrm{O} 3$ & Esférico & 0,52 & 8,14 & 0,70 & 0,22 & 1,45 & 0,97 & 0,77 & 0,93 \\
\hline \multicolumn{10}{|c|}{ Grade leve off-set com discos de $0,61 \mathrm{~m}$ de diâmetro } \\
\hline O1 & Esférico & 2,32 & 10,4 & 0,77 & 0,16 & 1,10 & 0,88 & 4,34 & 0,77 \\
\hline $\mathrm{O} 2$ & Esférico & 0,25 & 3,62 & 0,55 & 0,15 & 1,00 & 0,86 & 0,88 & 0,93 \\
\hline $\mathrm{O} 3$ & Esférico & 0,24 & 2,25 & 0,57 & 0,15 & 1,01 & 0,88 & 0,26 & 0,88 \\
\hline \multicolumn{10}{|c|}{ Sem preparo } \\
\hline & Esférico & 0,18 & 13,30 & 0,51 & 0,16 & 1,20 & 0,85 & 14,50 & 0,97 \\
\hline
\end{tabular}

de comparação utilizada na modelagem. ${ }^{(6)} \mathrm{RSS}$ : soma de quadrados de resíduos. ${ }^{(7)}$ ADE: avaliador de dependência espacial. 
Quanto à operação de escarificação, verifica-se que a ação das hastes foi até $0,30-0,35 \mathrm{~m}$ de profundidade (Figura 2), conforme regulagem do equipamento; observaram-se alguns pontos abaixo dessa profundidade, onde os valores de RP são próximos do limite de 6,0 MPa (Sene et al., 1985). Verificou-se maior ação das hastes até a camada de 0,25-0,30 m, onde foram encontrados valores de RP menores do que $2,0 \mathrm{MPa}$, o que se atribui à ação modificadora do

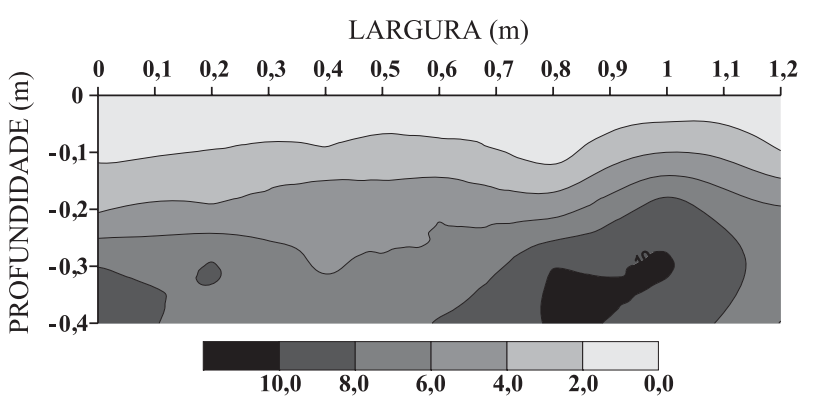

Figura 1. Mapa de isolinhas do atributo RP (MPa) no perfil do solo na área sem preparo.
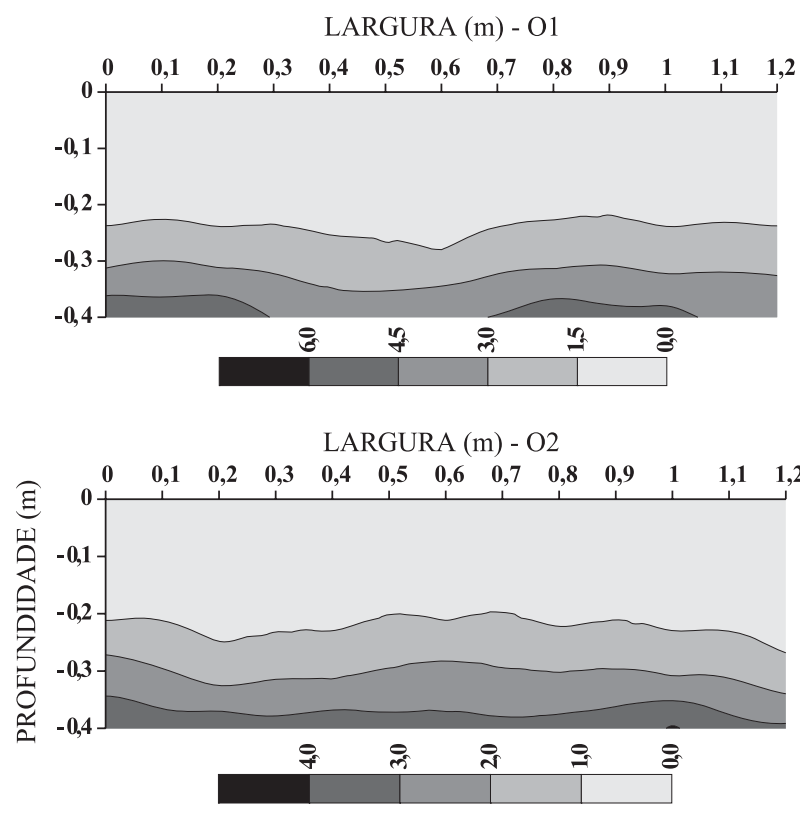

LARGURA (m) - O3

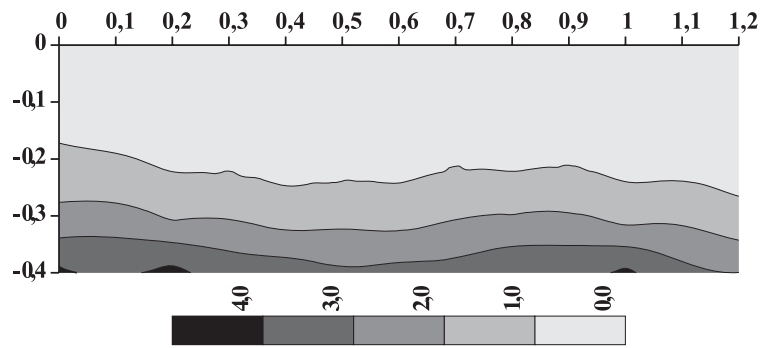

Figura 2. Mapa de isolinhas do atributo RP (MPa) no perfil do solo preparado com uma (O1), duas (O2) e três (O3) operações do escarificador. escarificador sobre a estrutura superficial do solo, caracterizando-o como equipamento de preparo periódico do solo, sendo indicado para romper camadas compactadas subsuperficiais. Os resultados são similares aos obtidos por Almeida et al. (2008) em Neossolo Quartzarênico e Argissolo VermelhoAmarelo, ambos com textura superficial arenosa, onde a RP máxima foi de 2,1 $\mathrm{MPa}$, mas a $\mathrm{RP}$ média foi inferior a 0,75 MPa.

De maneira geral, pôde-se verificar aumento da $\mathrm{RP}$ concomitantemente ao aumento da profundidade do solo (Figura 2), principalmente na camada de 0,30 $0,40 \mathrm{~m}$, local onde não ocorre a ação das hastes do escarificador e observa-se aumento no teor de argila do solo (Quadro 1). A redução da $\mathrm{RP}$ até a profundidade de aproximadamente $0,20 \mathrm{~m}$ deve-se à ação dos componentes ativos do escarificador, os quais atuam com maior eficiência nessa profundidade. Abreu et al. (2004) verificaram, em Argissolo Vermelho-Amarelo Distrófico arênico, que os menores valores de $\mathrm{RP}$ foram na profundidade de $0,15 \mathrm{~m}$ para o solo escarificado, em relação a semeadura direta, cultivo mínimo com crotalária e solo descoberto sem preparo, sendo o maior valor de $R P(1,6 \mathrm{MPa})$ encontrado no tratamento sob cultivo mínimo. Em relação ao número de operações, não se verificou considerável mudança na RP em profundidade (Figura 2).

Na operação da grade leve em tandem observaramse valores de RP de até $3,0 \mathrm{MPa}$ na camada até $0,30 \mathrm{~m}$ de profundidade e valores médios de 6,0 $\mathrm{MPa}$ abaixo desta (Figura 3). Verificou-se que a ação de diminuição da RP pelos componentes ativos desse implemento é a menor em relação aos outros, devido à sua menor capacidade de penetração, tanto pelo menor diâmetro do disco como pela sua menor massa. Entretanto, até a profundidade de $0,30 \mathrm{~m}$, os valores de RP estão ainda abaixo do limite crítico estabelecido por Sene et al. (1985). O aumento do número de operações da grade leve em tandem proporcionou menores valores de RP se comparados com os efeitos no solo com uma operação (O1). Os valores de RP observados foram de até 4,0 MPa para a profundidade de até $0,30 \mathrm{~m}$; , abaixo desta, observaram-se valores de até 10,0 MPa. Isso indica que a menor ação dos discos em relação aos outros equipamentos poderia ser compensada com maior número de passagens, mas isso resultaria em maior custo operacional.

No preparo com a grade leve off-set com discos de 0,56 m de diâmetro, observou-se alto valor de RP, atingindo valores de até $15,0 \mathrm{MPa}$ (Figura 4) abaixo da camada de $0,30 \mathrm{~m}$. Esse valor pode estar associado à translocação de argila do horizonte $\mathrm{A}$ para o $\mathrm{B}$, acarretando modificações no empacotamento de partículas ou unidades estruturais, conforme também observado por Silva et al. (2002). Estando o solo solto após a primeira gradagem, a distribuição da pressão aplicada na superfície pode ter ocorrido até maior profundidade, resultando na deformação plástica da 


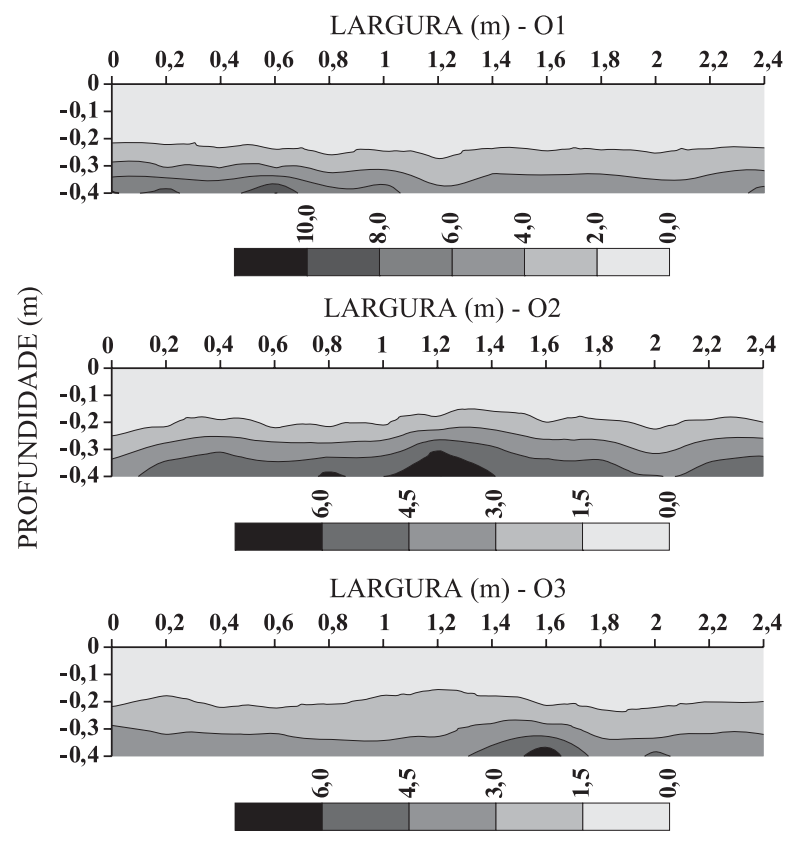

Figura 3. Mapa de isolinhas do atributo RP (MPa) no perfil do solo preparado com uma (O1), duas $(\mathrm{O} 2)$ e três (O3) operações da grade leve em tandem.
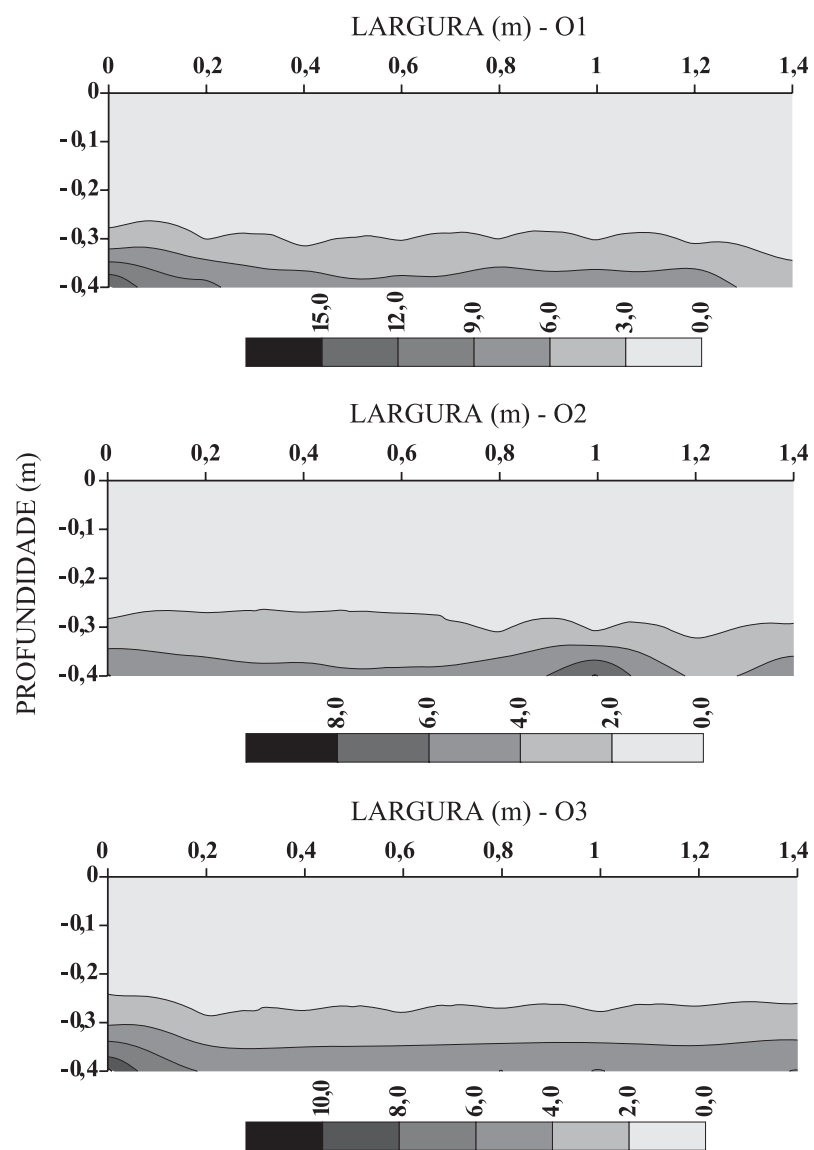

Figura 4. Mapa de isolinhas do atributo RP (MPa) no perfil do solo preparado com uma $(\mathrm{O} 1)$, duas (O2) e três (O3) operações da grade leve off-set com discos de 0,56 m de diâmetro. camada situada abaixo da profundidade de ação da grade. Com a ação dos discos na camada até $0,20-$ 0,30 m, verificaram-se valores de RP dentro dos padrões requeridos nas três intensidades de preparo, conforme observado por Sene et al. (1985).

No preparo com a grade leve off set com discos de 0,61 m de diâmetro, observaram-se valores baixos de RP com uma e duas operações, verificando-se valor maior do que 6,0 MPa apenas na área com uma operação (Figura 5), o que pode ser atribuído à presença de zonas com maior acumulação de argila (Silva et al., 2002) ou maior profundidade de ação dos discos, devido ao maior número de operações. Com apenas uma operação, os valores de RP foram adequados para cultivo (Sene et al., 1985), mostrando uniformidade da superfície, até 0,25-0,30 m de profundidade.

A ação das grades leves off-set com discos de 0,61 m e de $0,56 \mathrm{~m}$ foi mais profunda no perfil em relação à ação da grade leve em tandem", criando, nesse caso, um ambiente mais adequado ao estabelecimento de

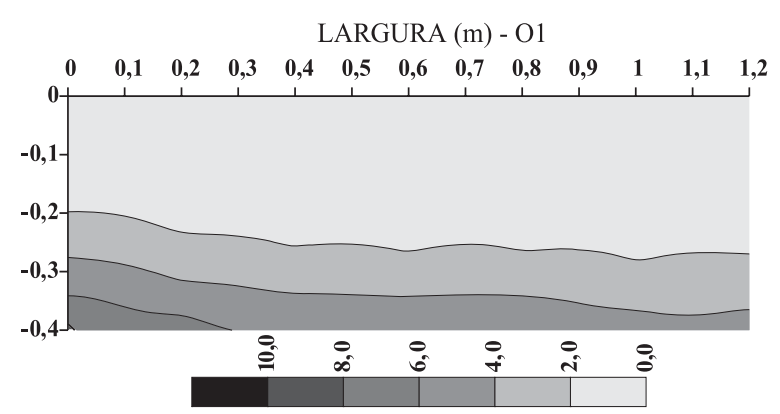

LARGURA (m) - O2

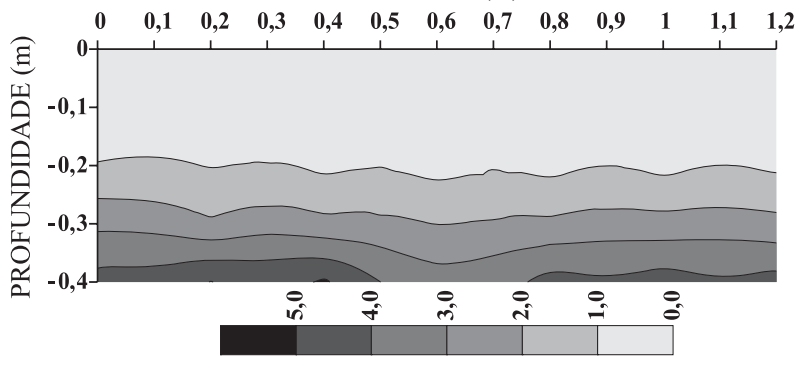

LARGURA (m) - O3

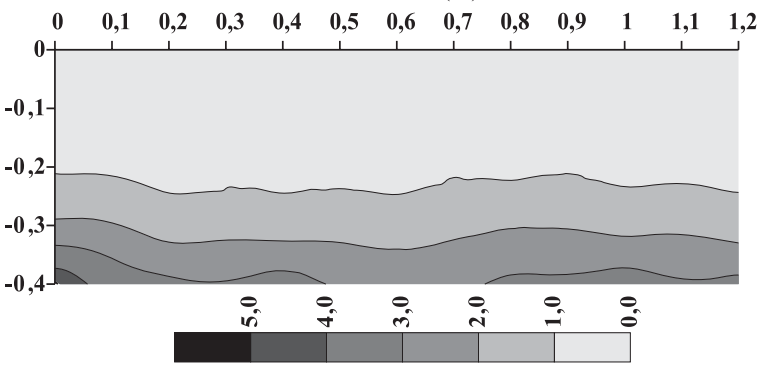

Figura 5. Mapa de isolinhas do atributo RP (MPa) no perfil do solo preparado com uma (O1), duas (O2) e três (O3) operações da grade leve off-set com discos de $0,61 \mathrm{~m}$ de diâmetro. 
culturas no que se refere a aumento do volume de solo para exploração pelo sistema radicular.

\section{CONCLUSÕES}

1. Os sistemas e a intensidade de preparo pouco interferiram na densidade do solo, sendo esta maior na camada de $0,10-0,20 \mathrm{~m}$.

2. A porosidade total determinada na camada superficial foi maior na área sem preparo e menor na área preparada com escarificador e grade leve off-set com discos de 0,61 m de diâmetro.

3. A área sem preparo apresentou heterogeneidade na resistência mecânica à penetração ao longo do perfil, com valores críticos abaixo de $0,30 \mathrm{~m}$ de profundidade. Os sistemas de preparo, independentemente do número de operações, reduziram a resistência mecânica à penetração em comparação ao solo original, sem preparo.

4. A resistência mecânica à penetração apresentou valores adequados até a profundidade de trabalho dos equipamentos e foi alta nas camadas situadas abaixo, exceto para o preparo com escarificador.

5. O efeito do preparo do solo no Argissolo Amarelo estudado foi pouco expressivo, pois este já apresenta condições de RP favoráveis ao cultivo até $0,30 \mathrm{~m}$ de profundidade, provavelmente devido à textura arenosa até essa profundidade.

\section{AGRADECIMENTOS}

Os autores agradecem à UNIVASF - Universidade Federal do Vale do São Francisco a concessão de bolsa de estudo ao segundo e ao terceiro autor.

\section{LITERATURA CITADA}

ABREU, S.L.; REICHERT, J.M. \& REINERT, D.J. Escarificação mecânica e biológica para a redução da compactação em Argissolo franco-arenoso sob plantio direto. R. Bras. Ci. Solo, 28:519-531, 2004.

ALMEIDA, C.X.; CENTURION, J.F.; FREDDI, O.S.; JORGE, R.F. \& BARBOSA, J.C. Funções de pedotransferência para a curva de resistência do solo à penetração. R. Bras. Ci. Solo, 32:2235-2243, 2008.

ALVARENGA, R.C.; FIGUEIREDO, A.F.; OLIVEIRA, W. \& FREIRE, J.C. Armazenamento de água em um podzólico Vermelho-Amarelo sob pastagem e cultivo anual. Ci. Prática, 7:48-57, 1983.

AMARAL, F.C.S.; SILVA, E.F. \& MELO, A.S. Caracterização pedológica e estudos de infiltração da água no solo em perímetros irrigados no Vale do São Francisco. Rio de Janeiro, Embrapa Solos, 2006. 104p.
ARAUJO, A.G. Máquinas para descompactação de solos. In: CASTRO FILHO, C.; MUZILLI, O. (Org.). Uso e manejo de solos de baixa aptidão agrícola. Londrina, Iapar, 1999. p.168-178.

ARAUJO, E.A.; LANI, J.L.; AMARAL, E.F. \& GUERRA, A. Uso da terra e propriedades físicas e químicas de Argissolo Amarelo distrófico na Amazônia Ocidental. R. Bras. Ci. Solo, 28:307-315, 2004.

BANZATTO, D.A. \& KRONKA, S.N. Experimentação agrícola. Jaboticabal, Funep, 2006. 237p.

BEUTLER, A.N.; CENTURION, J.F. \& SILVA, A.P. Comparação de penetrômetros na avaliação da compactação de latossolos. Eng. Agríc., 27:146-151, 2007.

BICKI, T.J. \& SIEMENS, J.C. Crop response to wheel traffic soil compaction. Trans. Am. Soc. Agric. Eng., 34:909-913, 1991.

BRASIL. Ministério da Agricultura. Levantamento exploratório - reconhecimento de solos do Estado de Pernambuco. Recife, SUDENE, 1973. 354p (Boletim Técnico, 26)

CAMARGO, O.A.; MONIZ, A.C.; JORGE, J.A. \& VALADARES, J.M.A.S. Métodos de análise química, mineralógica e física de solos do Instituto Agronômico de Campinas. Campinas, Instituto Agronômico de Campinas, 1986. 94p. (Boletim Técnico, 106)

CAMBARDELLA, C.A.; MOORMAN, T.B.; NOVAK, J.M.; PARKIN, T.B.; KARLEN, D.L.; TURCO, R.F. \& KONOPKA, A.E. Field-scale variability of soil properties in Central Iowa Soils. Soil Sci. Soc. Am. J., 58:1501-1511, 1994.

COSTA, F.S.; ALBUQUERQUER, J.A.; BAYER, C.; FONTOURA, S.M.V. \& WOBETO, C. Propriedades físicas de um latossolo Bruno afetadas pelos sistemas plantio direto e preparo convencional. R. Bras. Ci. Solo, 27:527535,2003 .

DEXTER, A. R. Soil physical quality. Part I. Theory, effects of soil texture, density, and organic matter, and effects on root growth. Geoderma, 120:201-214, 2004.

EMPRESA BRASILEIRA DE PESQUISA AGROPECUÁRIA EMBRAPA. Manual de métodos de análise do solo. Rio de Janeiro, Centro Nacional de Pesquisas de Solos, 1997. $212 \mathrm{p}$.

EMPRESA BRASILEIRA DE PESQUISA AGROPECUÁRIA EMBRAPA. Centro Nacional de Pesquisas de Solos. Sistema brasileiro de classificação de solos. Brasília, 2006. 370p.

GROHMANN, F. \& QUEIROZ NETO, J.P. Efeito da compactação artificial de dois solos limo-argilosos sobre a penetração das raízes de arroz. Bragantia, 25:421-431, 1966.

HILL, R. L. \& MEZA-MONTALVO, M. Long-term wheel traffic effects on soil physical properties under different tillage systems. Soil Sci. Soc. Am. J., 54:865-870, 1990.

HILLEL, D. Introduction to soil physics. San Diego, Academic Press, 1982. 364p. 
IIJIMA, M. \& KONO, Y. Interspecific differences of the root system structures of four cereal species as affected by soil compaction. Japanese J. Crop Sci., 60:130-138, 1991.

LANDIM, P.M.B. Análise estatística de dados geológicos. São Paulo, UNESP, 1998. 226p. (Ciência e Tecnologia).

LEBERT, M. \& HORN, R. A method to predict the mechanical strength of agricultural soils. Soil Tillage Res., 19:274286, 1991.

LETEY, J. The study of soil structure: science and art. Austr. J. Soil Res., 29:699-707, 1991.

MERCANTE, E.; URIBE-OPAZO, M.A. \& SOUZA, E.G. Variabilidade espacial e temporal da resistência mecânica do solo à penetração em áreas com e sem manejo químico localizado. R. Bras. Ci. Solo, 27:1149-1159, 2003.

MEROTTO, A.J. \& MUNDSTOCK, C.M. Wheat root growth as affected by soil strength. R. Bras. Ci. Solo, 23:197-202, 1999

SALVIANO, A.A.C.; VIEIRA, S.R. \& SPAROVEK, G. Variabilidade espacial de atributos de solo e de Crotalaria juncea L. em área severamente erodida. R. Bras. Ci. Solo, 22:115-122, 1998.

SENE, M.; VEPRASKAS, M.J.; NADERMAN, G.C. \& DENTON, H.P. Relationships of soil texture and structure to corn yield response to subsoiling. Soil Sci. Soc. Am. J., 49:422-427, 1985.

SILVA, M.S.L.; KLAMT, E.; CAVALCANTI, A.C. \& KROTH, P.L. Adensamento subsuperficial em solos do semi-árido: processos geológicos e/ou pedogenéticos. R. Bras. Ci. Solo, 6:314-320, 2002.

SILVA, G.J.; SOUZA, J.C. \& BIANCHINI, A. Crescimento da parte aérea de plantas cultivadas em vaso, submetidas à irrigação subsuperficial e a diferentes graus de compactação de um Latossolo Vermelho-escuro distrófico. R. Bras. Ci. Solo, 30:31-40, 2006.

SMUCKER, A.J.M. \& ERICKSON, A.E. Tillage and compactive modifications of gaseous flow and soil aeration. In: LARSON, W.E.; BLAKE, G.R.; ALLMARAS, R.R.; VOORHEES, W. B. \& GUPTA, S.C., eds. Mechanics related process in structured agricultural soils. The Netherlands, NATO Applied Science, 1989. v. 172. p. 205 221.
SOANE, B.D. The role of organic matter in soil compactibility: a review of some practical aspects. Soil Tillage Res., 16:179-201, 1990.

SOEHNE, W.H. Fundamentals of pressure distribution and soil compaction under tractor tires. Agric. Eng., 39:276290, 1958.

SOUZA, Z.M.; SILVA, M.L.S.; GUIMARÃES, G.L.; CAMPOS, D.T.S.; CARVALHO. M.P. \& PEREIRA, G.T. Variabilidade espacial de atributos físicos em um latossolo vermelho distrófico sob semeadura direta em Selvíria (MS). R. Bras. Ci. Solo, 25:699-707, 2001.

SPERA, S.T.; SANTOS, H.P.; FONTANELI, R.S. \& TOMM, G.O. Integração lavoura e pecuária e os atributos físicos de solo manejado sob sistema plantio direto. R. Bras. Ci. Solo, 33:129-136, 2009.

STOLF, R. Teoria e teste experimental de fórmulas de transformação dos dados de penetrômetro de impacto em resistência do solo. R. Bras. Ci. Solo, 15:229-235, 1991.

STOLF, R.; FERNANDES, J. \& FURLANI NETO, V. Penetrômetro de impacto - modelo IAA/Planalsucar STOLF. STAB, 1:18-23, 1983.

SUMNER, M.E. Uso atual do gesso no mundo em solos ácidos. In: SEMINÁRIO SOBRE O USO DO GESSO NA AGRICULTURA, 2., Uberaba, 1992. Anais... Uberaba, IBRAFOS, 1992. p.7-40.

TORRES, E. \& SARAIVA, O.F. Camadas de impedimento do solo em sistemas agrícolas com a soja. Londrina, Embrapa Soja, 1999. 58p.

VIEIRA, S.R. Geoestatística em estudos de variabilidade espacial do solo. In: NOVAIS, R.F.; ALVAREZ V., V.H. \& SHAEFER, C.E.G.R., eds. Tópicos em ciência do solo. Viçosa, MG, Sociedade Brasileira de Ciência do Solo, 2000. v.1. p.1-54.

WAGGER, M.G. \& DENTON, H.P. Influence of cover crop and wheel traffic on soil physical properties in continuous no-till corn. Soil Sci. Soc. Am. J., 53:1206-1210, 1989. 